\title{
How accurate are quotations and references in medical journals?
}

\author{
GERALD DE LACEY，CAROL RECORD， JENNY WADE
}

\begin{abstract}
The accuracy of quotations and references in six medical journals published during January 1984 was assessed. The original author was misquoted in $15 \%$ of all references, and most of the errors would have misled readers. Errors in citation of references occurred in $24 \%$, of which $8 \%$ were major errors-t that is, they prevented immediate identification of the source of the reference. Inaccurate quotations and citations are displeasing for the original author, misleading for the reader, and mean that untruths become "accepted fact."

Some suggestions for reducing these high levels of inaccuracy are that papers scheduled for publication with errors of citation should be returned to the author and checked completely and a permanent column specifically for misquotations could be inserted into the journal.
\end{abstract}

\section{Introduction}

Concern has been expressed regarding the accuracy of references in medical journals. ${ }^{1.4}$ Most assessments have been limited to citations and have not included the accuracy of statements made in regard to another author's work..$^{5-8}$ We present the results of a survey that looked at quotations as well as citations.

\section{Materials and methods \\ Six journals were selected. They comprised three general medical journals (the British Medical fournal, the Lancet, and the New England fournal of Medicine); two specialist journals (Clinical Radiology and the British fournal of Surgery); and a journal with a high proportion of review articles (the British fournal of Hospital Medicine). The first issue of each journal published during 1984 was obtained. All direct quotations of, indirect references to, or summaries of another author's work were identified, marked, and assigned a running number. Fifty references for each issue were then selected by random numbers. In this way quotations from original articles, reviews, leading articles, and correspondence were selected. Each reference was checked (by GdeL or CR) against the original source, and when the citation was not to the original source the source was traced where possible. Papers in}

University of Auckland Medical School, Auckland, New Zealand

GERALD DE LACEY, MA, FRCR, senior lecturer in radiology

Northwick Park Hospital and Clinical Research Centre, Harrow, Middlesex HA1 3UJ

CAROL RECORD, MA, MRCP, senior registrar in radiology

John Squire Medical Library, MRC Clinical Research Centre, Harrow, Middlesex HA1 3UJ

JENNY WADE, BA, ALA, head librarian

Correspondence to: Dr G de Lacey, Northwick Park Hospital and Clinical Research Centre, Harrow, Middlesex HAl 3UJ. foreign languages were translated as necessary. The results were recorded on a standard form. All references in which the scientific content was highly specialised or which required statistical or graphical skill were passed to an expert for assessment (see acknowledgments).

Quotations were classified with respect to accuracy as follows: 1 , precisely correct; 2 , incorporating a trivial error (these were classified as quotations in which errors of transcription did not alter or obscure the meaning of the quoted source); 3 , incorporating an error that was slightly misleading (this group covered quotations that misled or could mislead, but the errors were not sufficiently serious to destroy or fundamentally to alter the meaning of the source); and 4, incorporating an error seriously misrepresenting or bearing no resemblance to the original source. Errors of citation were graded into two categories by a medical librarian $(\mathrm{JW})$. Major errors of citation were those that prevented immediate identification of the source of reference. The remaining errors of citation were classified as minor. If a reference contained both a major and a minor error of citation it was classified as major only. When more than one quotation from the same reference was noted and the reference contained an error of citation this was counted only once. References not obtainable through normal interlibrary loan in the United Kingdom were classified as unverifiable.

\section{Results}

The prevalence of misquotations in the different journals ranged from $10 \%$ to $20 \%$ (table). Roughly one fifth of these were classified as trivial. A typical trivial error was a quotation by an author referring to "Nordic and European medical associations" when the original source had stated "Nordic and Common Market medical associations." Another author referred to " 42 patients" when the original source was " 42 abscesses in 40 patients."

Of the remaining misquotations, roughly half were classified as slightly misleading. An example was a quotation that reducing weight by decreasing intake of energy lowered the blood pressure in most obese hypertensive subjects. The original source, however, studied the effect of a combined low energy and low salt diet on weight and blood pressure. Another example was: "placental blood flow is maintained after giving this drug," referring to hydralazine. The source showed that $10 \mathrm{mg}$ hydralazine increased uteroplacental flow, but with $20 \mathrm{mg}$ hydralazine the uteroplacental blood flow decreased once arterial pressure fell below a critical level.

In the seriously misleading group several of the quotations had little resemblance to the original source. One correspondent said: "several studies have shown that the immediate memory span is intact," referring to patients with Korsakoff's syndrome. One of the two quoted sources was a paper on the psychological aspects of rehabilitation in cases of brain injury, with no mention of patients with Korsakoff's syndrome.

Another example of a quotation classified as seriously misleading was given in a letter that referred to a leading article in a journal. The letter included the statement that the "editorial contrasts the benign effects of cocaine on recreational users today with its sinister reputation in earlier years and concludes that a drug with dangerous potential may in some circumstances be contained and tamed." Though the article did state that "a drug with dangerous potential may in some circumstances be contained and tamed," it firmly and clearly qualified this statement and quite definitely had not come to this conclusion with regard to cocaine. Though this quotation was only a small part of an interesting letter regarding cocaine, this statement nevertheless misrepresented the leading article.

Misleading quotations were often due to oversimplification in summarising another author's figures. Referring to treatment of abscesses in the liver, it was stated that "in a subset of his patients treated with antibiotics and 
adequate drainage the mortality had fallen to $8 \%$." This was classified as misleading because the writers failed to say that this $8 \%$ mortality was in the subset, treated appropriately with both antibiotics and surgical drainage, who had only a solitary abscess. Those treated appropriately who had multiple abscesses had a mortality of $71 \%$, which had been made quite clear by the original authors. The statement as it stood was not inaccurate but misleading because it failed to point out this important distinction.

Errors occurred when a reference was not to the original source, and this appeared to be because the original source had not been read. One author (A) quoted a reference (B): "In the mid-1960's it was estimated that some 6-9\% of all pre-school children poisoned themselves." The paper (B) was published in 1965 but had itself been referring to findings in an earlier study (C). Scrutiny of the earliest paper (C) showed this to have found that $6.9 \%$ of the 1 to 4 year olds in an urban population in a 12 month period (1957-8) had poisoned themselves.

The incidence of errors of citation varied considerably among the journals, ranging from $8 \%$ to $46 \%$. Roughly a third of these were major errors, which were in the title of the journal, the volume, or the page numbers. The minor errors were in the title of the article or an author's name or initials.

\section{Discussion}

Generally references in scientific journals can be separated into two parts: firstly, the citation and, secondly, the quotation. The overall prevalence of errors of citation was $24 \%$, ranging from $8 \%$ to $46 \%$. These figures compare closely with the prevalences of error found by Goodrich and Roland in their report in 1977 assessing 10 different medical journals. ${ }^{5}$

How important are errors of citation? A minor error that does not prevent the paper being traced may not result in too much inconvenience. Errors or omissions of volume number or year, however, often cause serious problems for readers and librarians who later try to retrieve references. Similarly omissions and careless transcriptions of authors' names may create bibliographical problems, and such anomalies often survive in published reports for many years. Dobell describes a classic error of this type. ${ }^{9}$ The first part of the title of a paper published in a Czechoslovakian medical journal in 1887, "O uplavici"-that is, on dysentery-was transcribed as the author's name, Uplavici $\mathrm{O}$, by an abstracter and survived as such for some 50 years, acquiring a doctorate from an American indexer in 1910.

Errors regarding "accuracy of quotation" have not to our knowledge been previously assessed, apart from one paper that presented an evaluation of medical reporting in the lay press. ${ }^{10} \mathrm{We}$ found misquotations in $15 \%$ of all references, some of them trivial. The important errors are those that either slightly mislead the reader or seriously misrepresent the original. Of all references, $12 \%$ contained errors in these two categories. In most instances errors were caused by either carelessness or misleading use of language. The examples of misquotation shown in our results show the distinction we made between errors. A reference often represented only a minor aspect of a paper, and we did not attempt to record whether an error had a minor or major impact on the overall findings contained in the paper. There will of course be occasions when differences in interpretation of data or of statements will be a matter of opinion. We did not assess emphasis or arbitrate on differences in interpretation when the differences had been made clear. We assessed only whether the findings, claims, or statements in the original work had been referred to accurately. Of course some misquotations classified as seriously misleading might appear to be only slightly so (and vice versa) to another reader, and it would be difficult to eliminate completely such differences in opinion. The important finding, however, was any misleading error, whether slight or serious. It should be noted that the overall prevalence of errors we found is probably an underestimate, as all the journals contained some references that could not be verified (table).

Several consequences result from misquotation: the original authors will be displeased that their findings or statements have been misrepresented; readers will, of course, be misled; and if a journal accepts a high level of inaccuracy in its published papers healthy circumspection by critical readers may quite properly lead to a more general disbelief. For, as Roland emphasises, ${ }^{2}$ who can have confidence in a work in which there are mistakes, whether in the data, the interpretations, or the references? But perhaps the most serious consequence is the difficulty in correcting a major inaccuracy that may well become "accepted fact." A correction tucked away in some corner of a subsequent issue is unlikely to be read. Even where a correspondence column exists a letter of retraction published some weeks or months after an inaccurate quotation or statement may not be noted by an earlier reader. A classic example of fiction becoming accepted fact, despite a correction, has been given by Bassler in reference to a report in 1975 on the death of two marathon runners. " A letter in the New England Fournal of Medicine had stated that in one runner "at postmortem examination ischemic heart disease with a number of small infarcts was found," and that in a second runner "the postmortem examination showed coronary atheroma." These statements were subsequently retracted in the correspondence column of the same journal in 1976. In the first patient no postmortem examination had been performed and in the second there was no written record of necropsy or of findings at necropsy. Nevertheless, the original misleading statements had still not been satisfactorily corrected, as in 1982 they were referred to in two journals in support of a claim that $50 \%$ of deaths in marathon runners were due to severe coronary atherosclerosis. Though the above examples are not misquotations, they represent examples of erroneous figures or statements subsequently clearly corrected but nevertheless becoming accepted fact.

How might errors in references be reduced? It is surely important to reduce the high number of inaccurate citations found in this and similar surveys. ${ }^{45}$ These errors are understandable, but virtually all are readily and easily eliminated by careful checking of the final manuscript and galley proofs. But who should be responsible for eliminating errors-the author, the editor, or the referee? A few errors of citation will undoubtedly be due to inaccurate transcription by editorial staff or printers, and this will occur particularly with letters, where proofs are not seen by the author. It would, however, seem proper and sensible that accuracy of citation should be primarily the responsibility of the author. Checking all citations would mean a huge amount of work for editorial staff; for instance, two of the journals in this survey contained over 400 references in their January 1984 issue. Nevertheless, editors should accept some responsibility for accuracy and could, for example, sample references from each paper scheduled for publication. As soon as any error is found the paper could be returned with an instruction to check all citations again. This could be reinforced by informing the author that publication would now be purposely delayed and that the same sanction would apply if a further error was found on resubmission. This might appear unnecessarily officious, but high

\begin{tabular}{|c|c|c|c|c|c|c|c|c|c|c|c|c|}
\hline \multirow[b]{2}{*}{ Journal } & \multicolumn{4}{|c|}{ Misquotations } & \multicolumn{3}{|c|}{ Errors of citation } & \multirow[b]{2}{*}{$\begin{array}{c}\text { All } \\
\text { errors }\end{array}$} & \multirow{2}{*}{$\begin{array}{l}\text { No }(\%) \\
\text { not from } \\
\text { original } \\
\text { source }\end{array}$} & \multirow{2}{*}{$\begin{array}{c}\text { No }(\%) \\
\text { not } \\
\text { verifiable }\end{array}$} & \multirow{2}{*}{$\begin{array}{l}\text { Total No } \\
\text { of papers, } \\
\text { leading articles, } \\
\text { and letters }\end{array}$} & \multirow{2}{*}{$\begin{array}{l}\text { Total No of } \\
\text { references } \\
\text { cited in } \\
\text { bibliography }\end{array}$} \\
\hline & $\begin{array}{l}\text { Trivial } \\
\text { error }\end{array}$ & $\begin{array}{c}\text { Slightly } \\
\text { misleading }\end{array}$ & $\begin{array}{c}\text { Seriously } \\
\text { misleading }\end{array}$ & Total (\%) & Minor & Major & Total (\%) & & & & & \\
\hline $\begin{array}{l}\text { British foumal of Hospital Medicine } \\
\text { British fourmal of Surgery } \\
\text { British Medical foumal } \\
\text { Clinical Radiology } \\
\text { Lancet } \\
\text { New England fournal of Medicine }\end{array}$ & $\begin{array}{l}1 \\
2 \\
2 \\
1 \\
2\end{array}$ & $\begin{array}{l}5 \\
4 \\
3 \\
5 \\
1\end{array}$ & $\begin{array}{l}3 \\
2 \\
5 \\
2 \\
3 \\
4\end{array}$ & $\begin{array}{r}9(18) \\
6(12) \\
10(20) \\
9(18) \\
5(10) \\
6(12)\end{array}$ & $\begin{array}{r}7 \\
14 \\
10 \\
3 \\
8 \\
3\end{array}$ & $\begin{array}{l}6 \\
9 \\
3 \\
3 \\
4 \\
1\end{array}$ & $\begin{array}{l}13(26)^{\star} \\
23(46) \\
13(26) \\
6(12) \\
12(24) \\
4(8)\end{array}$ & $\begin{array}{l}22 \\
29 \\
23 \\
15 \\
17 \\
10\end{array}$ & $\begin{array}{ll}2 & (4) \\
2 & (4) \\
4 & (8) \\
1 & (2) \\
3 & (6) \\
5 & (10)\end{array}$ & $\begin{array}{l}6(12) \\
2(4) \\
2(4) \\
1 \quad(2) \\
3(6) \\
7(14)\end{array}$ & $\begin{array}{l}18 \\
35 \\
68 \\
19 \\
70 \\
28\end{array}$ & $\begin{array}{l}284 \\
481 \\
337 \\
220 \\
444 \\
370\end{array}$ \\
\hline
\end{tabular}

\This journal did not include titles of articles in references, thus there was less scope for minor errors of citation compared with other journals. 
prevalences of error of citation of $24 \%$ and over (including one of $46 \%$ ) might properly give cause for concern regarding the accuracy of other material contained within the papers. It is surely in the interests of editors and the more meticulous authors that this should not be the case.

In regard to the more serious matter of misquotation, the attitude of some editors concerning responsibility is not altogether clear. A recent leading article in the British Medical fournal discussed the advantages of speed, priority, and low cost of a new electronic journal, Clinical Notes On-line as against the attendant risks of inaccuracy, duplication, and triviality. ${ }^{12}$ The article claimed that this new journal was unique in abrogating editorial responsibility when it stated that "authors accept professional responsibility for their reports." This clearly indicates that the British Medical fournal accepts responsibility for accuracy in its papers, though it is not apparent whether this extends to quotations. If the British Medical Fournal accepts full responsibility for accuracy of quotations (and we emphasise that we do not think that this is reasonable, let alone manageable) then the position of that journal is unsatisfactory with an error in one out of every five quotations. Though we think that the primary responsibility for accuracy must lie with the author, editors would presumably not wish to abdicate all responsibility when prevalences of errors are high, simply because of the huge amount of work required for checking. Editors could help or stimulate authors to be more accurate-for example, journals might carry a column prominently entitled "Misquotations." The author misquoted would send the complaint to the editor, who, if he agreed, would refer the misquotation to this column. A classification that included serious misrepresentation should encourage some authors to be more careful and the more cavalier to be more circumspect. At an overall prevalence of misquotation of $15 \%$ none of the journals we scrutinised need be concerned that this new column would remain empty.

We thank the librarians of the Philson Library, University of Auckland Medical School, and the librarians of the MRC Clinical Research Centre, Harrow, for their help, and also the following experts for assessing some of the references: Dr David Hill, Division of Medical Statistics, MRC Clinical Research Centre, Harrow, and Drs Jonathan Reeve and John Garrow, Division of Clinical Sciences, MRC Clinical Research Centre, Harrow.

\section{References}

1 Relman AS. How reliable are letters? N Engl f Med 1983;308:1219-20.

2 Roland CG. Thoughts about medical writing. XXXVII. Verify your references. Anesth Analg 1976;55:717-8

3 Glass AR. Should letters be reviewed? N Engl f Med 1983;308:1232.

4 Place F. Verify your references: a word to medical writers. New York Medical foumal 1916;104:697-9.

5 Goodrich JE, Roland CG. Accuracy of published medical reference citations. Foumal of Technical Writing and Communication 1977;7:15-9.

6 Key JD, Roland CG. Reference accuracy in articles accepted for publication in the Archives of Physical Medicine and Rehabilitation. Arch Phys Med Rehabil 1977;58:136-7.

7 Broadus RN. An investigation of the validity of bibliographic citations. Fournal of the American Sociery for Information Science 1983;34:132-5.

$8 \mathrm{McKinin}$ EJ, Johnson ED. Techniques of online citation verification in NLM databases. Medical Reference Services Quarterly 1983;2(3):1-23.

9 Dobell C. Dr O Uplavici (1887-1938). Parasitology 1938;30:239-41.

10 Proudfoot AD, Proudfoot J. Medical reporting in the lay press. Med f Aust 1981;1:8-9.

11 Bassler TJ. Cardiomythology. Lancet 1984;i:788-9.

12 Lock S. Two cheers for the computer? Br Med F 1985;290:1609-10.

(Accepted 10 fuly 1985)

\section{CLINICAL CURIO}

\section{Pain in the ear? Aortic dissection!}

Late in January 1985 I was consulted by a 76 year old doctor about a pain deep in his right ear that radiated from tooth to eye and nose to mastoid. I had seen him regularly in recent years because of a trial fibrillation and cerebral embolism requiring anticoagulants. His dentist had wrongly taken the symptom to be a root abscess. We discussed the differential diagnosis of this deep "neuralgic" pain. It varied in intensity and duration; sometimes sudden, severe, and lasting minutes or hours. Posture had no influence, but he had noticed that when he first lay in bed with his right ear on the pillow pain would begin and delay onset of sleep. Attacks never wakened him. Cold wind would aggravate the pain. There was an unconvincing relation to an occipital prominence and a creaky neck. I could not come to a diagnosis.

Could it be temporal arteritis? I quickly dismissed this suggestion by showing temporal pulses and normal erythrocyte sedimentation rate. We sought a consultant opinion, and an otolaryngologist, who found no sign of disease in the ear, mouth, nose, sinuses, nasopharynx, or glossopharyngeal nerve, admitted him for $x$ ray examination and endoscopy. Neither of these showed any positive results, so he went to a neurologist for computed tomography.

At the end of March computed tomography of the head yielded normal results, and the erythrocyte sedimentation rate was $9 \mathrm{~mm}$ in first hour. On driving home his chest was rent by a sudden severe pain. "Dissection!" he exclaimed, and pulled on to the hard shoulder, where he collapsed. Before long he was discussing differential diagnosis with cardiologists. Admission chest $x$ ray films showed massive widening of the mediastinum, electrocardiography showed no infarction, and there was a bloody effusion at the base of the left lung. Emergency thoracic computed tomography was unfortunately equivocal, but my patient had had the foresight to stop taking warfarin four days before the event (a portent in the form of epistaxis).

After much gloomy prognostication he came home to gaze, perhaps not for long, at the hills and the sea. We agreed he should seek no more opinions. His residual complaints have been recurrent colicky abdominal pains and gross flatulence. His belly swells and there are other symptoms, less frequent or troublesome, such as dysphagia, a hoarse weak voice, hiccoughs, bouts of sneezing, fleeting pains in the left chest, and hunger pains in the epigastrium between meals, which are relieved by small meals and glasses of milk. He said "his innards were completely discombobulated." As some of these symptoms resembled those after vagotomy, I prescribed metoclopramide with some initial success. We are now trying dicyclomine.
He recently drew my attention to a paragraph in the British Medical fournal, "Pain in the ear-a presenting symptom of aortic dissection," which pointed out that the auricular nerve was a branch of the vagus. ${ }^{12} \mathrm{My}$ patient's gastrointestinal troubles were possibly due to implication of this nerve. Before dissection he used to talk of his wandering "hemicrania," but when no explanation could be found he began to suspect his doctors believed he was getting neurotic. Now, however, after hearing of the $B M \mathcal{F}$ reports, he thinks that there should be some type of medical enigma machine to decode such a gallimaufry of symptoms as he has presented.-L $S$ LEWIS, general practitioner, Wales.

1 Brewster MF. Pain in the ear-a presenting symptom of aortic dissection. BrMed f 1985;290:1517. 2 Hoffbrand BI, Hollman A. Pain in the ear-a presenting symptom of aortic dissection. $\mathrm{Br}$ Med $\mathcal{F}$ 1985;290:1112.

A 35 year old married man suffers from recurrent blushing and has done so all his life. He blushes at the slightest provocation. What is the prognosis with this condition and can any treatment be offered?

Recurrent blushing in situations of embarrassment, guilt, or ordinary social contact with the opposite sex is normal and common in young people. As social skills develop so the patient acquires the ability to control his reaction. Nevertheless, in some it may persist and at the age of 35 is likely to continue. The blushing is due to dilatation caused by the reflex inhibition of the tonic sympathetic vasoconstrictor activity in the cutaneous arterioles of the face and neck. A pharmacological approach therefore would be to use vasoconstrictor drugs such as sympathomimetric drugs or nicotine. These drugs would have to be taken continuously and probably in very large doses to suppress the blushing and would probably cause dangerous side effects such as hypertension. An alternative pharmacological approach might be to use a beta blocker drug to reduce cardiac output and tachycardia and perhaps, if the symptom is really disabling, it might be worth trying propranolol. A more logical and perhaps safer approach, however, would be to tackle the root cause of the problem - that is, the failure to acquire the social poise and skills appropriate to the situation. This problem might well be amenable to psychotherapeutic treatment with behavioural therapy, and I would suggest referral to a psychologist who has experience in such techniques.-E HOUSLEY, vascular physician, Edinburgh. 